\title{
Comparison of the evolutionary algorithm's performances on power flow analysis
}

\section{Evrimsel algoritma performanslarının güç akışı analizinde karşılaştırılması}

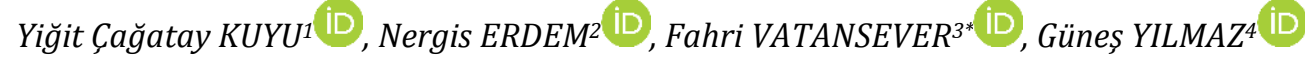 \\ 1,2,3,4Electrical-Electronics Engineering Department, Engineering Faculty, Uludag University, Bursa, Turkey. \\ yigitkuyu@uludag.edu.tr, nerdem@uludag.edu.tr, fahriv@uludag.edu.tr, gunesy@uludag.edu.tr
}

Received/Geliş Tarihi: 01.02.2016, Accepted/Kabul Tarihi: 07.06.2016

doi: $10.5505 /$ pajes.2016.89266

* Corresponding author/Yazıșllan Yazar

Research Article/Arastırma Makalesi

\begin{abstract}
Power flow in energy systems is one of the major problems. Several classical analysis methods are utilized for solving this problem. However, power generation limits, valve loading effects of units also makes the power flow problem become much harder to solve in the system. In this case, it is possible to achieve the most appropriate solutions with evolutionary algorithms. In this study, optimal power flow problems are solved under same beginning conditions, comprehensively performed with evolutionary algorithms which are recently used and associated algorithm performance is analyzed in IEEE 30-bus test system for two cases. Energy gains of algorithms are obtained; the best, worst and mean values found from optimization are evaluated; convergence analyses are performed comparatively. Thus the effectiveness and efficiency of evolutionary algorithms are clearly demonstrated on solution of optimal power flow problems.
\end{abstract}

Keywords: Optimal power flow problem, Optimization, Valve point effect, Fuel cost

\section{Introduction}

The optimal operation of the electricity grid in Carpentier's work since 1962 has become a topic of continuous improvement [1]. As technology developing, the customers need more energy and the optimal power flow (OPF) problem becomes more important. Therefore, many researchers have interested growingly in optimizing OPF problem [2]-[9]. In general, objective of the OPF problem is to minimize total fuel cost by adjusting optimal power system control variables while satisfying given set of power system constraints.

Several conventional optimization methods have been used to reduce the overall production cost for power flow problems in the literature [2]-[4]. Some of these methods have disadvantages because of the OPF problem which is nonlinear, non-convex and multimodal. In most cases, these methods have slow convergence, may suffer from local minima and they have unpredictable run time if number of variables increases. To overcome these deficiencies and limitations in conventional methods, evolutionary algorithms are developed. The major advantage of the evolutionary algorithms is that they can be applicable to various problems without getting stuck in local minima as well as have the ability to self-adapt a solution space when improving a solution as compared with conventional methods. Genetic algorithm (GA), differential evolution algorithm (DE), particle swarm optimization algorithm (PSO), simulated annealing algorithm (SA), and harmony search algorithm (HS) are often used in solution of
Öz

Enerii sistemlerinde güc akıșl, önemli problemlerden biridir. Bu problemin çözümü için farklı klasik çözümleme yöntemlerinden faydalanılmaktadır. Ancak sistemdeki jeneratörlerin güç üretme limitleri, valf yükleme etkileri gibi parametreler güç akışı probleminin ilgili yollarla çözümünü zorlastırmaktadır. Bu durumda evrimsel algoritmalarla en uygun çözümleri gerçekleștirmek mümkün olabilmektedir. Gerçekleștirilen çalıșmada optimal güç akıșı problemlerinin çözümü, iki farklı durumda 30 baralı IEEE test sisteminde güncel evrimsel algoritmalar ile eşit başlangıç șartlarıyla karșılaștırmalı olarak gerçekleștirilmiș ve ilgili algoritmaların performans değerlendirmeleri yapılmışır. Algoritmaların enerji kazanımları elde edilmis; optimizasyon sonucunda elde edilen en iyi en kötü ve ortalama değerleri hesaplanmış; yakınsama analizleri karșılaștırmalı olarak gerçekleștirilmiștir. Böylece optimal güç akıșı probleminin cözümünde evrimsel algoritmaların etkinlik ve verimlilikleri açılkça ortaya konulmuștur.

Anahtar kelimeler: Optimum güç akıșı problemi, Optimizasyon, Valf yükleme etkisi, Yakıt maliyeti

OPF problem in several studies [5]-[9]. However in the studies above related to solving OPF problems, the algorithms may not show own efficiency and robustness. When these studies are analyzed in terms of population size, number of execution and initial point, it is seen that different population size is preferred in some of studies and different number of execution is used as the stopping criterion. On the other hand, it is not possible to use same beginning point in different computers due to nature of algorithms which initial randomly. Using same initial seed gives support to algorithms for making comparison uniform. The aim of this study is to detailed comparative analysis in between recently-used eight optimization algorithms to solve power flow problems. All the algorithms were performed on the same platform to prevent misjudgment of the algorithms employed. By using same initial values, population size and number of execution, eight different algorithm analyses were carried out on IEEE-30 test bus system for two different cases of OPF problem.

This paper is organized as follows: In Section 2, formulation of OPF problem is declared. In Section 3, general structure of evolutionary algorithms is defined. In Section 4, implementation of OPF problem is described. Finally, In Section 5, simulation results are shown and discussed. 


\section{Problem formulation}

\subsection{Optimal power flow}

Optimal power flow optimization is a nonlinear constrained optimization problem and defined as follows:

$$
\begin{gathered}
\text { Minimize } f(x, u) \\
\text { Subject to } g(x, u)=0 \text { and } h(x, u) \leq 0
\end{gathered}
$$

In these functions, $x$ represents the state variables that can be seen in Eq. 3 and $u$ represents the control variables as shown in Eq. 4

$$
x^{T}=\left[P_{\text {slack }}, V_{L}, Q_{g}, S_{L}\right]
$$

In Eq. $3, x$ consists of slack bus $P_{\text {slack }}$, load bus voltage $V_{L}$ generator reactive power $Q_{g}$ and transmission line loading (line flow) $S_{L}$.

$$
u^{T}=\left[P_{g}, V_{g}, Q_{C}, T\right]
$$

Where $P_{g}$ is generator active power, $V_{g}$ is generation bus voltage, $Q_{C}$ is shunt VAR compensation and $T$ is transformers tap settings.

$$
\begin{gathered}
0=P_{g_{i}}-P_{L_{i}}-V_{i} \sum_{j=1}^{C} V_{j}\left\{G_{i j} \operatorname{Cos}\left(\theta_{i j}\right)+B_{i j} \operatorname{Sin}\left(\theta_{i j}\right)\right\} \\
i=1 \ldots C \\
0=Q_{g_{i}}+Q_{L_{i}}-V_{i} \sum_{j=1}^{C} V_{j}\left\{G_{i j} \operatorname{Sin}\left(\theta_{i j}\right)-B_{i j} \operatorname{Cos}\left(\theta_{i j}\right)\right\} \\
i=1 \ldots C
\end{gathered}
$$

$g(x, u)$ is the function of equality constraints and relies on typical load flow equations which are formulated in Eq. 5 and Eq. 6, where $P_{L_{i}}$ and $Q_{L_{i}}$ are the active and reactive load demand of $i^{\text {th }}$ line and $C$ is the number of buses in power system. $G_{i j}$ and $B_{i j}$ are real (conductance) and imaginary (susceptance) part of admittance matrix of power system. $\Theta_{i j}$ is the difference in voltage angle between bus $i$ and bus $j$ [7].

$h(x, u)$ is inequality constraints of the OPF problem. System operating constraints reflect the limits on physical devices in the power system. These constraints are given as follows:

$$
\begin{array}{cc}
P_{g_{i}}^{\min } \leq P_{g_{i}} \leq P_{g_{i}}^{\max } & i=1 \ldots C_{g} \\
Q_{g_{i}}^{\text {min }} \leq Q_{g_{i}} \leq Q_{g_{i}}^{\max } & i=1 \ldots C_{g} \\
V_{i}^{\min } \leq V_{i} \leq V_{i}^{\max } & i=1 \ldots C \\
T_{i}^{\min } \leq T_{i} \leq T_{i}^{\max } & i=1 \ldots C_{T} \\
Q_{C_{i}}^{\min } \leq Q_{C_{i}} \leq Q_{C_{i}}^{\max } & i=1 \ldots C_{C}
\end{array}
$$

Where $C_{g}, C_{T}$ and $C_{C}$ are the total number of generators, transformers and compensator devices, respectively. $P_{g_{i}}^{\min }$ $P_{g_{i}}^{\max }$ are lower and upper limits of active power for each generator. $Q_{g_{i}}^{\min }, Q_{g_{i}}^{\max }$ are lower and upper limits of reactive power for each generator. $V_{i}^{\min }, V_{i}^{\max }$ are lower and upper limits of voltage for each bus. $T_{i}^{\min }, T_{i}^{\max }$ are lower and upper limits of the transformer tap setting for each transformer [7].

\subsection{Objective function}

$(x, u)$ refers to the desired objective function to be minimized and represents total fuel cost in Eq. 12:

$$
f(x, u)=\sum_{i=1}^{c_{g}}\left(a_{i} P_{g_{i}}^{2}+b_{i} P_{g_{i}}+c_{i}\right)
$$

Where, $a_{i}, b_{i}$ and $c_{i}$ are the cost coefficients of $i^{t h}$ generator. Objective function $f$ is considered as the total fuel cost. Total fuel cost depends on the power of each generator and the cost coefficients.

\section{$2.3 \quad$ Valve point effect}

Considering the valve point effects of generators, a recurring rectifying sinusoidal term is joined to the principal quadratic cost function, as follows in Figure 1. With the valve point effects, cost function has some ripples because of these ripples; the number of local optima is increased in solution space [10]. Figure 1 represents the cost function of generators with/without the valve point effect [11]. Total fuel cost with valve point loading is given by Eq. 13 .

$$
f(x, u)=\sum_{i=1}^{c_{g}}\left(a_{i} P_{g_{i}}^{2}+b_{i} P_{g_{i}}+c_{i}+\left|d_{i} \operatorname{Sin}\left(e_{i}\left(P_{g_{i}}^{\min }-P_{g_{i}}\right)\right)\right|\right.
$$

Where, $d_{i}$ and $e_{i}$ are coefficients from valve point effect of $i^{t h}$ generator [11].

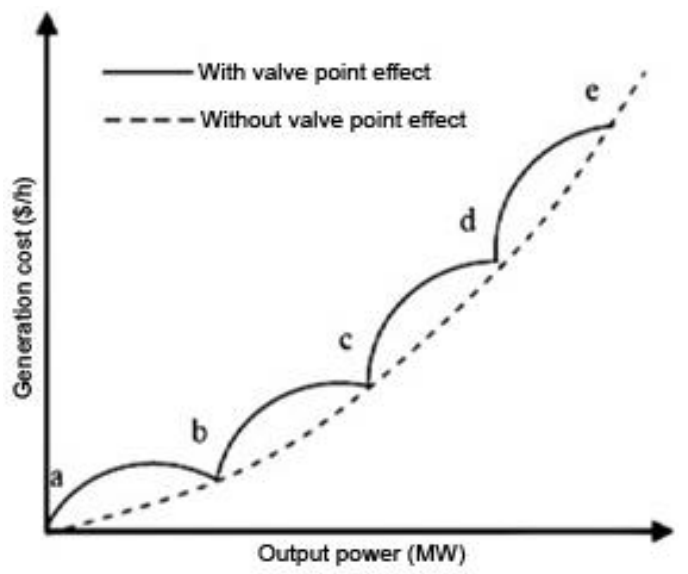

Figure 1: Cost function with and without valve point effect.

\section{Evolutionary algorithms}

In Table 1, the structure of algorithms used in OPF problems are summarized:

\section{Implementation of the algorithms to OPF problem}

This part makes a general statement of the all algorithms which is about how to solve OPF problem using objective function as gathered from Eq. 12. To solve this problem, algorithms generally follow these steps:

Step 1 : Define algorithm parameters and load input data from IEEE 30 bus test system.

Step 2 : Initialize algorithm randomly with initial population $X_{M}$, as follows: 
Table 1: Evolutionary algorithms used in OPF problem.

\footnotetext{
Artificial Bee Colony algorithm (ABC) [12]

1. Define number of colony size and limit value.

2.Generate initial food source positions.

3. Calculate initial nectar amounts.

4. Is the termination criteria satisfied?

a. If satisfied:

- Final food positions are best food positions.

b. (Else) If not satisfied:

- Determine the new food positions. process.

- Calculate the nectar amounts and apply selection

- Memorize the position of best food source so far.

- Go to Step 3.
}

Firefly algorithm (FF) [14]

1. Define number of fireflies, largest degree of attraction, degree of light attenuation and step factor.

2. Generate initial population randomly.

3. Calculate the relative brightness and attraction between

fireflies.

4. Find best Firefly.

5. Is the termination criteria satisfied?

a. If satisfied:

- Obtained minimum location from best Firefly.

b. (Else) If not satisfied:

- Test brightness for moving and update position.

- Go to Step 3.

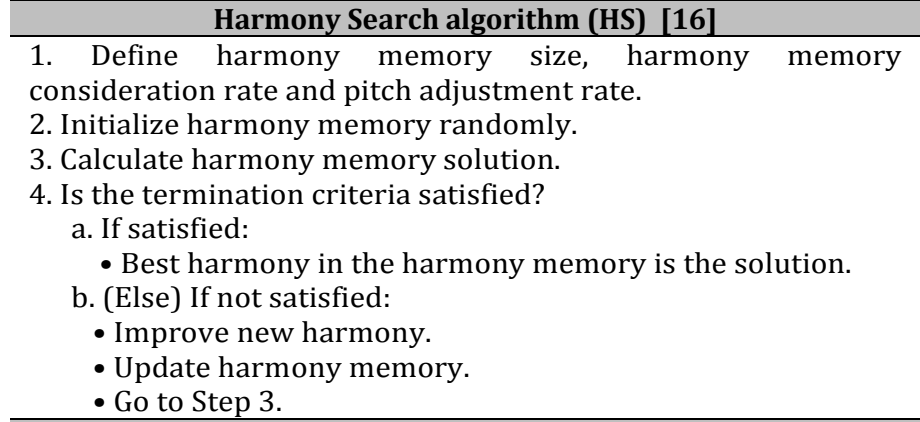

Harmony Search algorithm (HS) [16]

\section{Simulated Annealing algorithm (SA) [18]}

1. Define cooling schedule, initial and final temperatures.

2. Generate initial solutions.

3. Create a candidate list of solutions.

4. Evaluate solutions.

5. Find best admissible solution.

6 . Is the termination criteria satisfied?

a. If satisfied:

- Best solution is found.

b. (Else)If not satisfied:

- Update the temperature.

- Go to Step 3.

$$
X=\left[\begin{array}{c}
X_{1} \\
X_{2} \\
\ldots \\
X_{M}
\end{array}\right] \quad X_{i}=\left[X_{i, 1}, X_{i, 2}, \ldots, X_{i, D}\right] \quad i=1,2, \ldots M
$$

Where, $M$ is the population size and $D$ is the dimension of the problem. At the beginning, population is taken by algorithm randomly. It should be noted that whole algorithms use same initial population for equally comparison in this paper.

Step 3: Check the all constraints.
Cuckoo Search algorithm (CS) [13]

1. Define number of nests and probability of discovery egg by the host bird.

2. Generate initial population of host nests.

3. Calculate Cuckoo solutions.

4. Apply replacing process and determine Cuckoo societies.

5. Find current best Cuckoo.

6 . Is the termination criteria satisfied?

a. If satisfied:

- The best Cuckoo solution is found.

b. (Else) If not satisfied:

- Go to Step 3.

\section{Real Coded Genetic algorithm (RCGA) [15]}

1. Define population size, mutation probability and crossover probability.

2. Generate initial population randomly.

3. Calculate the fitness values of individuals.

4. Is the termination criteria satisfied?

a. If satisfied:

- Choose best individual.

b. (Else) If not satisfied:

- Generate new population via selection, crossover and mutation processes.

- Go to Step 3.

Particle Swarm Optimization algorithm (PSO) [17]

1. Define number of the swarm particles, initial velocity, cognitive parameter, social parameter, initial weight and scaling factor for inertia weight.

2. Generate initial particles randomly.

3. Calculate the fitness values of particles.

4. Is the termination criteria satisfied?

a. If satisfied:

- Choose best particle.

b. (Else) If not satisfied:

- Update velocity and position.

- Go to Step 3.

Differential Evolution algorithm (DE) [19]

1. Define population size, crossover rate and scaling factor.

2. Generate initial population randomly.

3. Calculate the fitness values of individuals.

4. Is the termination criteria satisfied?

a. If satisfied:

- Choose best individual.

b. (Else) If not satisfied:

- Generate new population via recombination and selection processes.

- Go to Step 3.
If any limit of constraint is violated, produce new individual $X_{i}$ with respect to Eq. 14 and transform the constrained OPF problem into unconstrained one by adding penalty term to $f\left(X_{i}, u\right)$ for each violated constraints.

Otherwise, go to Step 4.

Step 4:

a) Calculate the objective function in Eq. 12 using $X_{i}$,

b) Process the algorithm according to the obtained results from objective function and own searching criteria. The structures of all algorithms can be shown in Section 3. 
c) Choose best individual in the population that is found so far. This individual represents the variables of problem which are obtained from objective function.

Step 5: If the current number of execution reaches the predetermined maximum execution number, algorithm process is stopped, otherwise go to Step 4.

\section{Simulation results}

In this study, eight different algorithms are applied to OPF problem on IEEE 30-bus test system. Data of the 30-bus system can be achieved from [20]. As shown in Figure 2, IEEE 30-bus test system consists of four transformers and six generators, which has 283.4 MW total active demands, 126.2 MVAr total reactive demands. Related data of generators for IEEE 30 bus system which is online available in [20] are given in Table 2 [22].

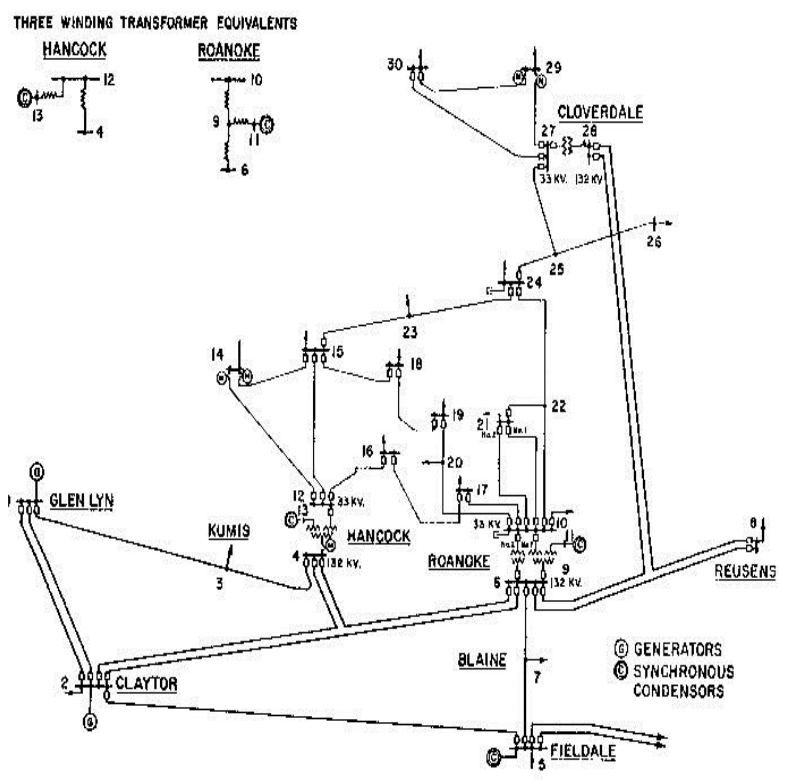

Figure 2: IEEE 30-bus test system [20].

This paper comprises two case studies to show the impact of valve point effect on the OPF problem, as follows:

Case 1 : Solution of OPF problem without valve point effect of generators,
Case 2 : Solution of OPF problem with valve point effect of generators.

All algorithms is performed with MATLAB [21] (computed with Intel(R) Core(TM) 2 Duo CPU $2.53 \mathrm{GHz}, 3$ GB RAM computer.) independently 10 times and tested on IEEE 30-bus test system to compare each other for both cases. The best method is determined based on total fuel cost and related analysis

Table 2: Fuel cost coefficients of generators for IEEE 30-bus test system [22].

\begin{tabular}{clllllll}
\hline $\begin{array}{c}\text { Generator } \\
\text { Number }\end{array}$ & \multicolumn{1}{c}{$\mathrm{a}$} & $\mathrm{b}$ & $\mathrm{c}$ & $\mathrm{d}$ & $\mathrm{e}$ & $\mathrm{P}_{\max }$ & $\mathrm{P}_{\min }$ \\
\hline G1 & 0.00375 & 2 & 0 & 18 & 0.037 & 250 & 50 \\
\hline G2 & 0.0175 & 1.75 & 0 & 16 & 0.038 & 80 & 20 \\
\hline G5 & 0.0625 & 1 & 0 & 14 & 0.04 & 50 & 15 \\
\hline G8 & 0.0083 & 3.25 & 0 & 12 & 0.045 & 35 & 10 \\
\hline G11 & 0.025 & 3 & 0 & 13 & 0.042 & 30 & 10 \\
\hline G13 & 0.025 & 3 & 0 & 13.5 & 0.041 & 40 & 12 \\
\hline
\end{tabular}

\subsection{Case 1: OPF problem solution without valve point} effect of generators

In the first case, OPF problem is solved without valve point effects by minimizing the objective function using Eq. 12 . Active power outputs for generators found by each algorithm are given in Table 3 . The obtained best, worst, mean values over 10 runs are shown in Table 4. It can be seen that in Table 3 , there is no big difference (less than \%1) in terms of fuel cost values of $\mathrm{ABC}, \mathrm{CS}, \mathrm{FF}, \mathrm{PSO}$, and DE. However, DE and PSO find lesser costs compared to other three algorithms.

As shown from Figure 3 which shows the convergence performance of different algorithms, CS is not more successful in solving case 1 of OPF problem compared with PSO and DE. Despite that, CS can converge to own optimum point (local solution) in lesser executions. On the other hand, $\mathrm{ABC}$ is more robust algorithm dealing with stability and accuracy. It can be also observed that SA and FF are not stable with big fluctuation and they make more number of executions to reach optimum point than other algorithms.

Results presented in Table 4 show that if accuracy of all algorithms are analyzed just based on best values, PSO is better choice to solve case 1 of OPF problem. It can be easily seen in Table 4, SA and RCGA find significantly worst solution than other algorithms.

Table 3: Power generations of all generators found by different algorithms for case 1 .

\begin{tabular}{cccccccc}
\hline Algorithms & $\mathrm{P}_{\mathrm{g} 1}(\mathrm{MW})$ & $\mathrm{P}_{\mathrm{g} 2}(\mathrm{MW})$ & $\mathrm{P}_{\mathrm{g} 3}(\mathrm{MW})$ & $\mathrm{P}_{\mathrm{g} 4}(\mathrm{MW})$ & $\mathrm{P}_{\mathrm{g} 5}(\mathrm{MW})$ & $\mathrm{P}_{\mathrm{g} 6}(\mathrm{MW})$ & Fuel cost $(\$ / \mathrm{h})$ \\
\hline ABC & 176.720 & 48.830 & 21.477 & 21.673 & 12.099 & 12 & 801.937 \\
CS & 176.787 & 48.802 & 21.490 & 21.591 & 12.134 & 12 & 801.938 \\
FF & 175.951 & 50.704 & 19.197 & 24.926 & 10.006 & 12.082 & 802.539 \\
RCGA & 170.893 & 47.952 & 20.473 & 22.385 & 13.918 & 16.786 & 803.046 \\
HS & 176.357 & 48.499 & 21.823 & 21.714 & 12.329 & 12.027 & 801.941 \\
PSO & 177.089 & 48.920 & 21.505 & 21.877 & 12.168 & 11.261 & 801.922 \\
SA & 175.314 & 49.718 & 21.227 & 22.673 & 13.004 & 10.779 & 803.349 \\
DE & 177.089 & 48.920 & 21.505 & 21.877 & 12.169 & 11.261 & 801.922 \\
\hline
\end{tabular}




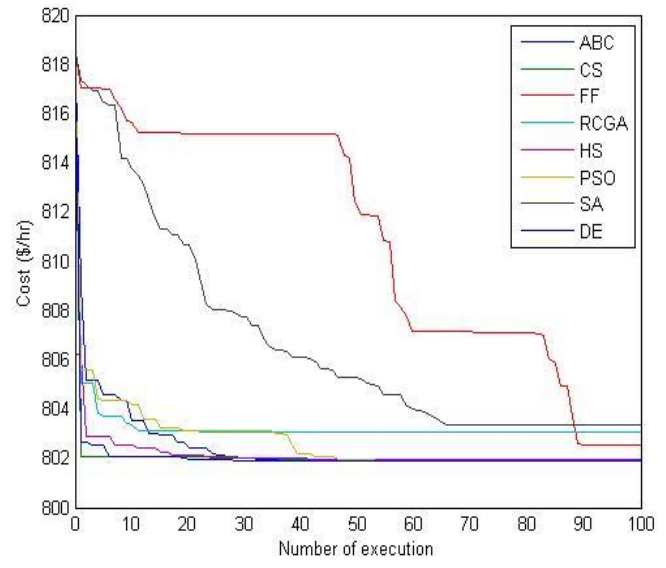

Figure 3: Convergence performance of different algorithms for Case 1.

Table 4: Best, mean and worst cost values for different algorithms in Case 1.

\begin{tabular}{llcc}
\hline & Worst & Mean & Best \\
\hline ABC & 802.038 & 801.948 & 801.937 \\
\hline CS & 801.949 & 801.939 & 801.938 \\
\hline FF & 807.831 & 804.840 & 802.539 \\
\hline RCGA & 806.786 & 804.213 & 803.046 \\
\hline HS & 801.955 & 801.947 & 801.941 \\
\hline PSO & 801.958 & 801.929 & 801.922 \\
\hline SA & 815.243 & 807.032 & 803.349 \\
\hline DE & 802.022 & 801.934 & 801.922 \\
\hline
\end{tabular}

As given from Figure 4, energy saving ratios are alike but when the convergence of the different algorithms are compared, each algorithm converges to different points in different number of executions as shown in Figure 3.

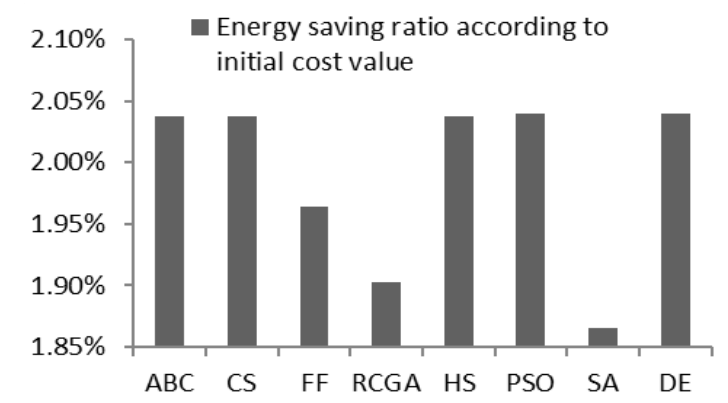

Figure 4: Energy saving ratios for case 1.

\subsection{Case 2: OPF problem solution by considering valve point effect of generators}

In this case, valve point effect is considered and the data is listed in Table 2. Active power outputs for generators are given in Table 5 and convergence performance of different algorithms related to case 2 is shown in Figure 5. Best, mean, worst values for the results of case 2 obtained by associated algorithms are given in Table 6 . From the results in Table 6 , best, mean, worst solutions found by each algorithm are different from the solution of case 1 due to valve point effect which increases computational costs of algorithms. As an example, without considering valve point effect, mean value of costs found by all algorithms is almost $803.22 \$ / \mathrm{h}$ but considering this effect, the cost rises to almost $831.88 \$ / \mathrm{h}$.

As shown from Figure 5, HS, SA and FF have more number of executions (more than 80 ) to settle at the minimum point. Moreover, significant differences exist among these three algorithms for best cost values and HS gives better results compared with two of them.

As seen from Table 6 unlike to case 1, RCGA finds worst result and CS gives best result with small difference compared with ABC. On the other hand, similar to case 1 as shown in Figure 5, FF and SA don't only make more numbers of executions but also give worse result compared to rest of algorithms. Of course, FF, SA and RCGA are not suitable for solving case 2 as compared to other algorithms. In general, if the balance between best and worst values of algorithms are analyzed which are shown in Table 6, the results of ABC, PSO, DE and HS are very identical and if small differences are not taken into account (less than \%1), this problem can be solved with these four algorithms for case 2 .

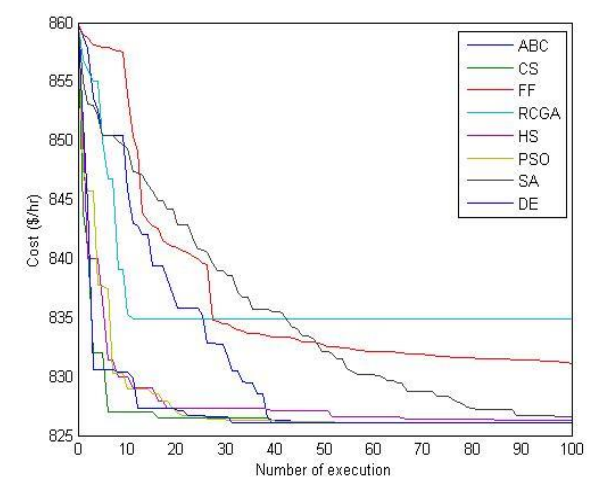

Figure 5: Convergence performance of different algorithms for Case 2.

Table 5: Power generations of all generators found by different algorithms for case 2.

\begin{tabular}{|c|c|c|c|c|c|c|c|}
\hline Algorithms & $\begin{array}{c}\mathrm{P}_{\mathrm{g} 1} \\
(\mathrm{MW})\end{array}$ & $\begin{array}{c}\mathrm{P}_{\mathrm{g} 2} \\
(\mathrm{MW})\end{array}$ & $\begin{array}{c}\mathrm{P}_{\mathrm{g} 3} \\
(\mathrm{MW})\end{array}$ & $\begin{array}{c}\mathrm{Pg} 4 \\
(\mathrm{MW})\end{array}$ & $\begin{array}{c}P_{g 5} \\
(\mathrm{MW})\end{array}$ & $\begin{array}{c}\mathrm{P}_{\mathrm{g} 6} \\
(\mathrm{MW})\end{array}$ & $\begin{array}{c}\text { Fuel cost } \\
(\$ / \mathrm{h})\end{array}$ \\
\hline $\mathrm{ABC}$ & 219.814 & 27.861 & 16.017 & 10 & 10.031 & 12 & 826.053 \\
\hline CS & 219.814 & 28.013 & 15.905 & 10 & 10 & 12 & 826.033 \\
\hline $\mathrm{FF}$ & 217.893 & 21.077 & 23.364 & 10.183 & 10.021 & 12.565 & 831.102 \\
\hline RCGA & 198.657 & 42.315 & 17.926 & 11.355 & 11.330 & 12.853 & 834.834 \\
\hline HS & 219.626 & 27.002 & 16.825 & 10.129 & 10.045 & 12.021 & 826.240 \\
\hline PSO & 219.815 & 28.278 & 15.657 & 10 & 10 & 12.001 & 826.039 \\
\hline SA & 219.534 & 27.047 & 16.582 & 9.904 & 10.667 & 11.912 & 826.613 \\
\hline $\mathrm{DE}$ & 219.815 & 27.986 & 15.933 & 10 & 10 & 11.995 & 826.035 \\
\hline
\end{tabular}


As shown in Figure 6, energy saving ratios according to initial cost values are very similar except RCGA but the number of executions taken to convergence solution is different when compared with each other.

Table 6: Best, mean and worst cost values for different algorithms in Case 2.

\begin{tabular}{cccc}
\hline & Worst & Mean & Best \\
\hline ABC & 827.15 & 826.191 & 826.05 \\
CS & 828.05 & 826.239 & 826.03 \\
FF & 843.92 & 839.551 & 831.1 \\
RCGA & 848.411 & 842.635 & 834.834 \\
HS & 827.22 & 826.529 & 826.24 \\
PSO & 827.53 & 826.412 & 826.04 \\
SA & 855.07 & 841.394 & 826.61 \\
DE & 827.04 & 826.138 & 826.04 \\
\hline
\end{tabular}

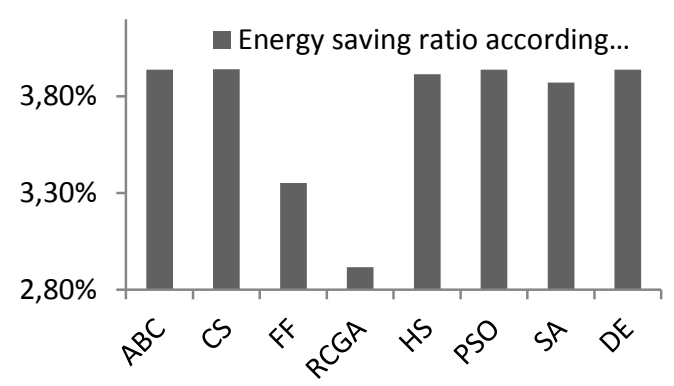

Figure 6: Energy saving ratio for case 2.

\section{Conclusions}

The OPF problems become difficult to solve because of large number of constraints and nonlinearity of OPF problems for mathematicians as well as for engineers. In this paper, eight different algorithms are successfully performed on two different cases of OPF problem. Discussing valve point effect and complex constraints create a challenge for algorithms to reach minimum cost. We have pointed out equal competition between algorithms in this challenge and also compared to all algorithms comprehensively on the OPF problem under equal conditions for both cases. The equally analysis showed that each algorithm has own strength and weakness when dealing with OPF problem. The outcome of this research helps not only provide an equal comparison between whole algorithms but also helps to show us which algorithm works more efficiently on which cases.

\section{References}

[1] Carpentier J. "Contribution to the economic dispatch problem". Bulletin de la Societe Francoise des Electriciens, 3(8), 431-447, 1962.

[2] Sun DI, Ashley B, Brewer B, Hughes, A, Tinney W. "Optimal power flow by newton approach". IEEE Transaction on Power Apparatus and Systems, 103(10), 2864-2880, 1984.

[3] Habiabollahzadeh H, Luo GX, Semlyen A. "Hydrothermal optimal power flow based on combined linear and nonlinear programming methodology". IEEE Transaction on Power Apparatus and Systems, 4(2), 530-537, 1989.

[4] Momoh JA, El-Hawary ME, Adapa R. "A review of selected optimal power flow literature to 1993. II. Newton, linear programming and interior point methods". IEEE Transactions Power Systems, 14, 105-111, 1999.
[5] Bakistzis A, Biskas P, Zoumas C, Petridis V. "Optimal power flow by enhanced genetic algorithm". IEEE Transaction on Power Systems, 17, 229-236, 2002.

[6] Abou EEA, Abido M, Spea S. "Optimal power flow using differential evolution algorithm". Electrical Engineering, 91(2), 69-78, 2009.

[7] Abido M. "Optimal power flow using particle swarm optimization". International Journal of Electrical Power \& Energy Systems, 24(7), 563-571, 2002.

[8] Roa-Sepulveda C, Pavez-Lazo B. "A solution to the optimal power flow using simulated annealing". International Journal of Electrical Power \& Energy Systems, 25(1), 47-57, 2003.

[9] Sinsuphan N, Leeton U, Kulworawanichpong T. "Optimal power flow solution using improved harmony search method". Applied Soft Computing, 13(5), 2364-2374, 2013.

[10] Aruldoss T, Victoire A, Jeyakumar AE. "Hybrid PSO-SQP for economic dispatch with valve-point effect". Electric Power Systems Research, 71(1), 51-59, 2004.

[11] Nikham T, Narimani M, Azizipanah-Abarghooee R. "A new hybrid algorithm for optimal power flow considering prohibited zones and valve point effect". Energy Conversion and Management, 58, 79-95, 2012.

[12] Karaboga D. "An Idea based on honey bee swarm for numerical optimization". Computer Engineering Department, Erciyes University, Erciyes, Turkey, Technical Report, TR06, 2005.

[13] Yang X, Deb S. "Cuckoo Search via lévy flights". World Congress on Nature \& Biologically Inspired Computing, Coimbatore, India, 9-11 December 2009.

[14] Yang X, He X. "Firefly algorithm: recent advances and applications". International Journal Swarm Intelligence, 1(1), 36-50, 2013.

[15] Goldberg D. "Real-Coded genetic algorithms, virtual alphabets, and blocking". Complex Systems, 2, 139-168, 1991.

[16] Yang X. Harmony Search as a Metaheuristic Algorithm. Editors: Geem ZW. Music-Inspired Harmony Search Algorithm, 1-14, Berlin, Heidelberg, Germany, Springer, 2009.

[17] Kennedy, J, Eberhart RC. "Particle swarm optimization". Proceedings of IEEE International Conference on Neural Networks, Piscataway, New Jersey, USA, 27 November1 December, 1995.

[18] Kirkpatrick S, Vecchi M, Gelatt C. "Optimization by simulated annealing". Science, 220(4598), 671-680, 1983.

[19] Storn R, Price K. "Differential Evolution-a Simple and Efficient Adaptive Scheme for Global Optimization over Continuous Spaces". International Computer Science Institute, Berkley, USA, Technical Report, TR95, 1995.

[20] Power Flow Test Cases, IEEE 30-Bus Test System Data. https://www.ee.washington.edu/research/pstca7pf30/ pg_tca30bus.htm (10.09.2015).

[21] The MathWorks Inc. "MATLAB (2007)".

[22] Niknam T, Narimani MR, Azizipanah-Abarghooee R. "A new hybrid algorithm for optimal power flow considering prohibited zones and valve point effect". Energy Conversion and Management, 58, 197-206, 2012. 